\author{
ANNA BROSCH \\ Uniwersytet Śląski w Katowicach
}

\title{
SMARTFON W KLASIE: OD ZABAWKI DO NARZĘDZIA EDUKACYJNEGO
}

\begin{abstract}
AвSTRACt. Brosch Anna, Smartfon w klasie: Od zabawki do narzędzia edukacyjnego [The Smartphone in the Classroom: from a Toy to an Educational Tool]. Studia Edukacyjne nr 48, 2018, Poznań 2018, pp. 335347. Adam Mickiewicz University Press. ISSN 1233-6688. DOI: 10.14746/ se.2018.48.22

Today's children are growing up in a digital age that is far different from that of previous generations. Young children's use of interactive screen media such as smartphones is increasing rapidly. A variety of mobile devices are all around, but they are still not accessible enough at schools, where the use of smartphones is usually forbidden.

The aim of this research was to discover teachers' opinion about using smartphones in class. The qualitative methodology was used in this study to analyse in depth the contextual factors concerning the use of smartphones during the education process. The analysis was based on data from 32 interviews with primary school teachers. The results of the study have shown that teachers do not incorporate smartphones into the education process, despite their positive attitude towards this kind of mobile devices.
\end{abstract}

Key words: education, m-learning, primary school, teachers, smartphone

\section{Szkoła versus nowe technologie}

Jeszcze trzydzieści lat temu, mimo że w powszechnym użyciu poza szkołą były długopisy, standardowym narzędziem pisarskim w szkole było wieczne pióro, za pomocą którego uczniowie nabywali umiejętność pisania kaligrafując litery w zeszycie z liniaturą, w sposób opracowany jeszcze w czasach gęsiego pióra. Umiejętność ta, opanowana przez ówczesnych uczniów, nigdy nie została jednak wykorzystana przez nich w dorosłym życiu, a szkoła powinna przecież kształcić umiejętność wykorzystania zdobytej wiedzy. Obecnie, kiedy pióro zastąpiła klawiatura komputera, a nawet ekran dotykowy smartfonu czy tabletu, uczniowie swoje pierwsze doświadczenia pisarskie 
nabywają kaligrafując litery ołówkami. Z jednej strony rozwijają $w$ ten sposób sprawność manualną, lecz z drugiej strony należałoby się zastanowić, czy ołówek nie jest już narzędziem anachronicznym?

Rosnącą przepaść technologiczną między szkołą a otaczającą rzeczywistością społeczną dostrzegł już w 1969 roku kanadyjski wizjoner mediów Marshall McLuhan, który w wywiadzie dla Magazynu „Playboy” stwierdził, iż

nasz system edukacji jest ciągłym oglądaniem się za siebie. To ginący i przestarzały układ wzniesiony na piśmiennych wartościach oraz cząstkowych i sklasyfikowanych danych, które są zupełnie niedostosowane do potrzeb pierwszego pokolenia telewizyjnego ${ }^{1}$.

Choć wypowiedź ta liczy sobie blisko pół wieku i odnosi się do ekspansji nowego masowego medium - telewizji, jednak dzisiaj, u progu kolejnego stulecia nie straciła na aktualności.

Postęp techniczny, jaki obserwuje się $\mathrm{w}$ ostatnich latach zmienia naszą rzeczywistość, w związku z czym należy pogodzić się z faktem, iż nowe technologie stały się jednym z elementów kontekstu społeczno-wychowawczego najmłodszego pokolenia. Wyposażenie domów w różnorodne urządzenia mobilne stało się standardem, a zjawisko konwergencji mediów zaciera granice w przestrzeni medialnej między kanałami, formami i formatami przepływu treści. Proces ten spowodował zmiany w sposobie korzystania z mediów z biernego na czynny².

Wśród różnorodnych urządzeń mobilnych niewątpliwie czołowe miejsce zajmuje smartfon, który stał się nie tylko medium komunikacyjnym, ale wręcz przedmiotem pierwszej potrzeby. To przenośne urządzenie, łączące funkcję telefonu komórkowego i kieszonkowego komputera (PDA - Personal Digital Assistant), z wbudowanym aparatem cyfrowym i kamerą oraz blisko pięciocalowym ekranem, stanowi doskonałą alternatywę dla innych urządzeń mobilnych, jak notebook czy tablet. Obecnie popularność smartfonów rośnie dynamicznie również wśród najmłodszych użytkowników, którzy korzystają z tych urządzeń nie tylko w celach rozrywkowych. Jak pokazują badania przeprowadzonego przez Gemius Polska na zlecenie platformy edukacyjnej Squla.pl, co trzecie dziecko od 6 do 12 lat wykorzystuje smartfon jako pomoc w nauce ${ }^{3}$. Trudno się temu dziwić, ponieważ podstawowe oprogramowanie

${ }^{1}$ E. Mcluhan, F. Zingrone (red.), M. McLuhan. Wybór tekstów, przekł. E. Różalska, J.M. Stokłosa, Poznań 2001, s. 354.

${ }^{2}$ M. Jachimowski, Wptyw konwergencji mediów na ksztattowanie się przestrzeni medialnej, Rocznik Prasoznawczy, 2012, 6, s. 37-57.

3 "Generacja Z od A do Z". Rola nowych technologii w nauce i rozwoju dzieci w wieku 6-12 lat, Raport analityczny opracowany w 2015 roku przez Gemius Polska na zlecenie platformy edukacyjnej Squla.pl. http://di.com.pl/files/Raport_Generacja_Z_od_A_do_Z.pdf [dostęp: 12.11.2016]. 
smartfonów umożliwia prezentację grafiki oraz odtwarzanie i tworzenie materiałów audio i wideo. Ponadto, smartfon podłączony do Sieci daje możliwość wyszukiwania różnorodnych informacji i oferuje całą gamę możliwości komunikacyjnych. Pod względem edukacyjnym nieoceniony jest również szereg bezpłatnych aplikacji, których wykorzystanie w celu nauki może ograniczać jedynie wyobraźnia użytkownika.

Tymczasem, standardy technologiczne szkoły znacznie odbiegają od przyjętych w środowisku pozaszkolnym, a smartfon figuruje najczęściej w wewnętrznych regulaminach pod paragrafem dotyczącym zakazów i kar. Jak wynika z raportu wydanego przez Instytut Badań Edukacyjnych w 2013 roku, we współczesnej szkole wciąż znaczącą przewagę pod względem dostępności mają media analogowe, jak odtwarzacze płyt CD i radiomagnetofony, natomiast rzutnik i tablica multimedialna stanowią w szkołach urządzenia deficytowe ${ }^{4}$. Smartfon z kolei w ogóle nie był brany pod uwage jako potencjalne medium edukacyjne.

Niewątpliwie, wyposażenie szkół w nowoczesne urządzenia mobilne nie jest przedsięwzięciem łatwym w realizacji, dlatego może warto zastanowić się, w jaki sposób wykorzystać potencjał edukacyjny urządzenia, które prawie każdy uczeń nosi w kieszeni?

\section{Zrozumieć pokolenie smartfonu}

Współczesne pokolenie przekraczające mury szkoły jest zgoła odmienne od swoich rodziców czy nauczycieli i stąd doczekało się wielu neologizmów stanowiących próbę jego nazwania zgodnie z najnowszymi trendami rozwoju technologicznego. W literaturze można zatem spotkać takie określenia, jak Gen Z, Post-Millenials, iGeneration ${ }^{5}$ czy The New Silent Generation ${ }^{6}$, które nawiązują do cyfrowego charakteru interakcji i potrzeby permanentnego bycia online. Obejmuje osoby urodzone po 1995 roku i wychowywane w erze cyfrowej, dla których nowe media stanowią naturalne środowisko egzystencji i często towarzyszą im już od pierwszych chwil życia. Australijski badacz społeczny Mark McCrindle w wywiadzie dla „New York Times” zwrócił jednak uwagę, iż dzieci urodzone po 2010 roku diametralnie się różnią od swoich starszych kolegów, ponieważ od pierwszych chwil życia mają przed oczyma ekrany

${ }^{4}$ M. Federowicz i in., Czas pracy i warunki pracy w relacjach nauczycieli. Raport tematyczny z badania, Instytut Badań Edukacyjnych, Warszawa 2013, s. 48.

${ }^{5} \mathrm{M}$. McCrindle, E. Wolfinger, The ABC of XYZ: understanding the global generations, Bella Vista 2014.

${ }^{6}$ S.L. Saldik, The New Recruit: What your Association needs to know about X, Y \& Z, Andover 2007, s. 18. 
pełniące funkcję smoczków, zabawek i narzędzi edukacyjnych. W związku $\mathrm{z}$ tym zaproponował wyłonienie nowego pokolenia o nazwie Generation Alpha, jako pierwszego pokolenia XXI wieku .

Bez względu na przyjęte nazewnictwo niewątpliwie jest to pierwsze pokolenie, dla którego świat nowych technologii jest światem zastanym, a jego zasadniczą cechę stanowi zaawansowana znajomość oraz biegłość w obsłudze urządzeń cyfrowych. Świadczą o tym badania przeprowadzone w Stanach Zjednoczonych pod koniec 2014 roku, z których wynika, że dla ponad jednej trzeciej dzieci poniżej pierwszego roku życia smartfon lub tablet stanowi zabawkę. Podobna tendencja widoczna jest również w Polsce. Jak wynika z badań przeprowadzonych przez Millward Brown S.A. na zlecenie Fundacji Dzieci Niczyje, blisko połowa dzieci poniżej drugiego roku życia korzysta z urządzeń mobilnych, przy czym $30 \%$ z nich czyni to codziennie. Ponadto, zainteresowanie urządzeniami mobilnymi wzrasta wraz z wiekiem dziecka. Wśród pięcio- i sześciolatków już tylko niespełna 17\% nie korzysta w ogóle z tego typu urządzeń9.

Niewątpliwie „inicjacja mobilna” dzieci ma miejsce bardzo wcześnie, a szeroki dostęp do cyfrowych urządzeń mobilnych jak smartfony, Wi-Fi czy interaktywne gry komputerowe sprawia, że najmłodsze pokolenie jest określane jako „urodzeni z chipem"10. Oczywiście, nie pozostaje to bez wpływu na ich rozwój psychofizyczny i sposób postrzegania rzeczywistości. Znawca problematyki nowych mediów Marc Prensky określił najmłodsze pokolenie mianem cyfrowych tubylców, jednocześnie formułując tezę, iż w wyniku interakcji z nowymi mediami mózgi cyfrowych tubylców, kształtowane raczej przez ekran niż książkę, różnią się od mózgów wcześniejszych generacji11. Amerykańscy badacze Gary Small oraz Gigi Vorgan ukuli nawet nowy termin iBrain. Na podstawie badań eksperymentalnych stwierdzili powstanie nowych ścieżek neuronalnych u nałogowych internautów, których nie odnaleziono u osób niekorzystających z Internetu, co skutkuje zmianą sposobu

7 A. Williams, Meet Alpha: The Next 'Next Generation', “The New York Times” z 19.09.2015. https://www.nytimes.com/2015/09/19/fashion/meet-alpha-the-next-next-generation.html? $\mathrm{r}=0$ [dostęp: 7.10.2016].

${ }^{8}$ H.K. Kabali i in., Exposure and Use of Mobile Media Devices by Young Children, Pediatrics, 2015, 136(6), http://pediatrics.aappublications.org/content/early/2015/10/28/peds.20152151 [dostęp: 11.10.2016].

9 A. Bąk, Korzystanie z urządzeń mobilnych przez małe dzieci w Polsce. Wyniki badania ilościowego, Warszawa 2015.

${ }^{10} \mathrm{~S}$. Abram, J. Luther, Born with the chip: The next generation will profoundly impact both library service and the culture within the profession, Library Journal, 2004, 129, s. 34-37.

${ }^{11}$ M. Prensky, Digital Natives. Digital Immigrants, Part 1, On the Horizon, 2001, 9(5), s.1-6. 
myślenia z linearnego na hipertekstowy i wielowątkowy ${ }^{12}$. Ponadto, niektórzy badacze sugerują, że współczesne dzieci cechuje niższy poziom uspołecznienia oraz większa niecierpliwość niż przedstawicieli poprzednich pokoleń. Przyczyna tkwi zapewne w samotnym spędzaniu czasu wolnego w swoim pokoju zamiast zabawy na podwórku lub spędzania czasu z rodzicami ${ }^{13}$.

Sprawia to, że cyfrowi tubylcy mają szczególne preferencje związane ze stylem nauki, sposobem zdobywania informacji i funkcjonowaniem w społeczeństwie, które znacząco różnią się od pokolenia ludzi epoki przedcyfrowej. W związku z tym wymagają stosowania odmiennych metod i środków edukacyjnych, abstrahując od tego w jakim kontekście - pozytywnym czy negatywnym - jest postrzegane dorastanie w świece cyfrowym.

\section{Stosunek nauczycieli do wykorzystania smartfonu w edukacji w świetle badań własnych}

Zagadnienie wyposażenia szkół w urządzenia mobilne oraz sposób ich wykorzystania w edukacji były już przedmiotem wielu badań, których wyniki zostały opublikowane $\mathrm{w}$ postaci raportów. Te najistotniejsze, $\mathrm{z}$ punktu widzenia poruszanej problematyki, zostały przytoczone $w$ pierwszej części niniejszego tekstu. W związku z tym pojawiła się konieczność postawienia pytań o powody, motywacje i przyczyny, którymi kierują się nauczyciele unikając włączenia smartfonów w proces lekcyjny.

W tym wypadku adekwatną metodę badań stanowił wywiad pogłębiony, umożliwiający indywidualne potraktowanie respondentów, a tym samym uchwycenie głębszego kontekstu badanego zjawiska. Nauczyciele współtworzą bowiem grupę formalną, jaką jest szkoła, a co za tym idzie - utożsamiają się z jej szeroko pojętą kulturą i organizacją, podejmują wspólne inicjatywy, reprodukując pewien wspólny charakter działania, stąd wniknięcie w tę strukturę poprzez badania umiejscowione $\mathrm{w}$ paradygmacie ilościowym jest utrudnione lub wręcz niemożliwe.

Celem prowadzonych w ostatnim kwartale 2016 roku badań było zatem poznanie powodów, jakimi kierują się nauczyciele podejmując decyzję o zakazie używania telefonów podczas lekcji, jak również zrozumienie ich postaw względem tego nowoczesnego medium jako potencjalnego narzędzia edukacyjnego. Wywiady zostały przeprowadzone z trzydziestoma dwoma nauczycielami pracującymi w szkołach podstawowych na terenie województwa śląskiego. Ponieważ w badaniach jakościowych w większości przypadków nie

${ }^{12}$ G.W. Small, G. Vorgan, iBrain: Surviving the Technological Alteration of the Modern Mind, New York 2008.

${ }^{13}$ J.U. McNeal, The Kids Market: Myths and Realities, New York 1999. 
stosuje się sformalizowanej (tzn. losowej) selekcji, zastosowano wygodny dobór próby, zakładający dobór tych przypadków, które w danych okolicznościach są najłatwiej dostępne ${ }^{14}$. Zasadniczym kryterium doboru było zatrudnienie w szkole podstawowej, przy czym zwrócono uwagę, by próba składała się z nauczycieli poszczególnych przedmiotów nauczania. W efekcie, w badanej grupie znalazło się sześcioro nauczycieli edukacji wczesnoszkolnej, pięcioro języków obcych, czworo informatyki i techniki, czworo geografii i przyrody, troje języka polskiego, troje wychowania fizycznego, dwoje historii oraz po jednym nauczycielu religii, chemii, fizyki, plastyki i muzyki. W wywiadach wzięło udział 6 mężczyzn i 26 kobiet, a wiek badanych mieścił się $\mathrm{w}$ przedziale od 26 do 48 lat.

Analiza zebranego materiału empirycznego pozwoliła uzyskać odpowiedzi na następujące pytania badawcze:

1. Jaka jest opinia nauczycieli odnośnie smartfonu jako medium komunikacyjnego?

2. Czy i w jakich obszarach edukacji nauczyciele dostrzegają możliwość wykorzystania smartfonu?

3. Jakie są powody unikania przez nauczycieli korzystania ze smartfonu jako narzędzia edukacyjnego podczas lekcji?

Jak się okazuje, badani nauczyciele mają pozytywną opinię o smartfonie i wszyscy zgodnie przyznali, że są jego posiadaczami. Uważają smartfon za urządzenie bardzo intuicyjne w obsłudze, która nie przysparza im większych problemów, choć jednocześnie nie potrafili podać specyfikacji technicznej swoich urządzeń. Interesujące, iż każdy badany przyznał, iż pierwszą czynnością po zakupie smartfonu jest jego personalizacja, czyli dostosowanie wyglądu i obsługi urządzenia do własnych preferencji. Wśród niezliczonych funkcji smartfonu badani najczęściej wykorzystują budzik i aparat fotograficzny, podkreślając, iż ze względu na swoje rozmiary jest znacznie wygodniejszy od tradycyjnego aparatu cyfrowego. Niewiele mniejszą popularnością cieszy się kalkulator i kalendarz. Natomiast nieliczni badani, bo zaledwie dziewięcioro, korzysta z aplikacji kompatybilnych z systemem operacyjnym Android. Wśród nich znalazła się nawigacja samochodowa oraz aplikacje umożliwiające monitorowanie osobistych danych dotyczących wysiłku fizycznego czy zużycia kalorii. Znikome zainteresowanie miały natomiast aplikacje związane z bankowością i płatnościami mobilnymi, gdyż korzystanie z takowych zadeklarował tylko jeden badany nauczyciel. Na tej podstawie można stwierdzić, iż badani nauczyciele mają raczej pozytywną opinię o smartfonie i traktują go jak urządzenie codziennego użytku. Jednakże, niewielka grupa wykorzystuje smartfon w sposób wychodzący poza jego podstawowe funk-

${ }^{14}$ U. Flick, Projektowanie badania jakościowego, przekł. P. Tomanek, Warszawa 2010, s. 58. 
cje. Powodem tego, jak przyznali, jest słaba znajomość możliwości technicznych urządzenia i stąd obawa przed eksperymentowaniem $\mathrm{z}$ instalowaniem dodatkowego oprogramowania. Jednocześnie, korzystający z aplikacji mobilnych mają świadomość, czym jest smartfon i jakie możliwości daje korzystanie $\mathrm{z}$ tych aplikacji. Wykazują przy tym rozwagę $\mathrm{w}$ zarządzaniu nimi, instalując aplikacje tylko wówczas, gdy są przekonani o ich użyteczności. Natomiast, kiedy aplikacja nie spełnia ich oczekiwań, pozbywają się jej, by nie obciążać pamięci urządzenia. Badani mają zatem bardzo pozytywną opinię o smartfonie, z którego korzystają nie tylko w celach komunikacyjnych. Jednocześnie przyznają, że nie wykorzystują wszystkich jego możliwości ze względu na brak wiedzy i umiejętności w tym zakresie, przy czym największe trudności miały kobiety powyżej 35 . roku życia.

Brak wystarczających kompetencji cyfrowych nauczycieli znajduje odzwierciedlenie $\mathrm{w}$ braku postrzegania smartfonu jako narzędzia edukacyjnego. Dla większości z nich smartfon stanowi narzędzie służące głównie do komunikowania się z rodzicami uczniów i ewentualnie informowania ich o postępach i trudnościach edukacyjnych dzieci. Do wykorzystania smartfonu na lekcji podchodzą bardzo sceptycznie, tłumacząc, iż „dzieci dużo czasu spędzają $\mathrm{w}$ domu przed ekranami, więc w szkole powinny od nich odpocząć". Jak również nadmierne korzystanie z mediów elektronicznych „przyczynia się do zanikania umiejętności poprawnego wypowiadania się oraz pisania i powoduje ubożenie kreatywności uczniów". Blisko połowa badanych przyznała, iż zna lub słyszała o aplikacjach edukacyjnych, lecz nie bardzo widzą możliwość wykorzystania ich w szkole. Podkreślają, iż włączenie telefonów w proces edukacyjny zdezorganizuje klasę, co może skutkować trudnościami z zachowaniem dyscypliny podczas lekcji. Ponadto, nie wszyscy uczniowie mają smartfony, w związku z czym zaplanowanie lekcji z wykorzystaniem smartfonów jest niemożliwe. Zaledwie dwóch nauczycieli edukacji wczesnoszkolnej poleca uczniom, w porozumieniu z rodzicami, wykorzystanie aplikacji edukacyjnych $\mathrm{w}$ smartfonach do utrwalania wiadomości. Telefon komórkowy w szkole jest przez większość badanych postrzegany jako potencjalne zagrożenie, począwszy od zakłócania toku lekcji, a na nagrywaniu kolegów i nauczycieli skończywszy. Jeden nauczyciel przyznał, że w jego szkole miał miejsce happy slapping ${ }^{15}$ i zostały wobec ucznia wyciągnięte konsekwencje. Nauczyciele mają więc do telefonów w szkole stosunek zakazowy, co znajduje wyraz w szkolnych regulaminach. W szkołach, w których pracują korzystanie z telefonu podczas lekcji jest zabronione, a tylko $\mathrm{w}$ dwóch dopuszcza się korzystanie $\mathrm{z}$ telefonu $\mathrm{w}$ czasie przerw, przy czym $\mathrm{w}$ jednej pod warunkiem ustawienia

${ }^{15}$ Proceder polegający na filmowaniu aktu przemocy wobec rówieśników. 
trybu „milczy”. Jednocześnie nauczyciele są zgodni, iż decyzja o zakazie używania telefonów w szkole jest w pełni uzasadniona. Pozwala bowiem uniknąć kłopotliwych sytuacji związanych z niewłaściwym użytkowaniem urządzenia, jego kradzieżą lub zgubieniem, a przede wszystkim zapobiega segregacji uczniów „na lepszych i gorszych” ze względu na model smartfonu lub fakt posiadania lub nieposiadania urządzenia. W tym kontekście podejście nauczycieli do smartfonu w szkole można skwitować parafrazą słów piosenki Boba Marleya "No Phone, No Cry” i wraz z zakazem używania telefonów w szkole znikają wszelkie problemy z nim związane. Pojawia się jednak pytanie: gdzie w takim razie dzieci mają nauczyć się "fonetykiety", czyli swoistego savoir vivre'u, określającego zasady i normy korzystania ze smartfonu w różnych sytuacjach społecznych? Zdaniem nauczycieli, to na rodzicach spoczywa ten obowiązek, a tylko siedmioro z nich przeprowadziło z uczniami zajęcia dotyczące właściwego korzystania z telefonów - głównie nauczyciele edukacji wczesnoszkolnej. Rodzice powinni niewątpliwie przygotować dziecko do poruszania się w świecie mediów mobilnych, jednak należy podkreślić, że rodzina stanowi odmienne od szkoły środowisko społeczne, w którym telefon nie jest urządzeniem zakazanym. A zatem, nie występują tam sytuacje, jakie mają miejsce w szkole. W konsekwencji, jedynym możliwym sposobem nauczenia dziecka właściwego korzystania z urządzenia może być metoda perswazji, która jednak w tych okolicznościach nie wydaje się skuteczna. Zdumiewa przy tym podejście nauczycieli do korzystania z telefonów przez pracowników szkoły. Nauczyciele zgodnie stwierdzili, iż podczas przerw korzystają z telefonów bez ograniczeń, a czworo przyznało, że „zdarzyło mi się odebrać ważny telefon podczas lekcji" (sic!).

Powyższa analiza pokazuje, że szkole potrzebna jest swoista rewolucja, lecz nie tyle w zakresie infrastruktury technologicznej, ile w zmianie sposobu myślenia o nowych technologiach, pozwalającej na wykorzystanie mediów mobilnych w celu skuteczniejszego uczenia się i nauczania. Tymczasem, nauczyciele wydają się „,równie sparaliżowani naszym nowym światem elektroniki, jak ludzie prymitywni sparaliżowani są naszą cywilizacją druku i mechanizacji"16.

Stąd, istnieje paląca potrzeba ciągłego podnoszenia kompetencji cyfrowych nauczycieli, ponieważ nie tylko są to dla nich technologie mało znane, ale też zazwyczaj nie posługują się nimi tak biegle, jak uczniowie. Ponadto, taka postawa nauczycieli względem wykorzystania nowych technologii podczas lekcji może wynikać z faktu, iż ich nawyki percepcyjne kształtowały się $\mathrm{w}$ poprzedniej epoce, co w znacznym stopniu utrudnia zrozumienie specyfiki

${ }^{16}$ E. Mcluhan, F. Zingrone (red.), M. McLuhan, s. 222. 
współczesnej generacji. Dopiero rzetelna wiedza związana z genezą i konsekwencjami digitalizacji młodego pokolenia pozwoli dostrzec całą gamę różnic między uczniami a ich rodzicami i nauczycielami, a w efekcie dostosować metody i środki nauczania do ich potrzeb i możliwości.

\section{W poszukiwaniu rozwiązań - metoda na pokolenie smartfonu}

Wykorzystanie smartfonu jako narzędzia wspomagającego naukę powinno być rozpatrywane w kontekście edukacji mobilnej (ang. m-learning), obejmującej „szeroką gamę możliwości edukacyjnych, jakie stwarza połączenie technologii mobilnych, bezprzewodowych sieci oraz technologii e-kształcenia"17. Edukacja mobilna nie jest pojęciem jednoznacznym, stąd w literaturze przedmiotu można spotkać wiele prób jej zdefiniowania, gdzie jedni autorzy podkreślają możliwość uczenia się na odległość, inni natomiast osobisty charakter i dostępność urządzeń $^{18}$. Z teoretycznego punktu widzenia ważne są aspekty zaakcentowane przez El-Hussein i Cronje, które zakładają „mobilność technologii, mobilność osób uczących się i mobilność uczenia się"19. Ideą mobilnej edukacji jest zatem stworzenie społeczności uczących się, w której zarówno ucznia, jak i nauczyciela nie ogranicza program nauczania oraz gdzie kluczowe znaczenie dla indywidualizacji toku kształcenia, konstruowania treści dydaktycznych i budowania relacji społecznych ma niezależność miejsca i czasu ${ }^{20}$. W odniesieniu do urządzeń mobilnych, Lechosław Hojnacki zwraca uwagę natomiast na ich „duży potencjał indywidualizacji i personalizacji przekazu, połączony z techniczną łatwością interkomunikacji” "21. Biorąc pod uwagę fakt, iż urządzenia mobilne największą popularnością cieszą się wśród młodego pokolenia, którego percepcję poznawczą pobudzają multimedialne i interaktywne materiały dydaktyczne, warto zastanowić się nad możliwościami wykorzystania smartfonów w edukacji. Tym bardziej, że proces edukacyjny jest skuteczny, jeśli nauka odbywa się na podstawie konkretnego doświadczenia lub w odniesieniu do dotychczasowych doświadczeń uczniów.

${ }^{17}$ L. Hojnacki, Pokolenie m-learningu - nowe wyzwanie dla szkoty, E-mentor, 2006, 1(13), s. 26. http://goo.gl/BMJLs. [dostęp: 12.11.2016].

18 A. Kukulska-Hulme, J. Traxler, Mobile learning: a handbook for educators and trainers, New York 2005.

${ }^{19}$ M.O.M. El-Hussein, J.C. Cronje, Defining Mobile Learning in the Higher Education Landscape, Educational Technology \& Society, 2010, 13(3), s. 12-21. http://ifets.info/journals/13_3/3.pdf [dostęp: 14.11.216].

${ }_{20}$ W. Susłow, T. Królikowski, M-learning, więc uczenie się w terenie, Zeszyty Naukowe Politechniki Poznańskiej, 2005, 8, s. 12.

${ }^{21}$ L. Hojnacki, Pokolenie m-learningu. 
Spektrum możliwości wykorzystania smartfonu w edukacji jest bardzo szerokie. Można go wykorzystać, jak uczynił Peter Bergman, do informowania rodziców poprzez SMS-y o zadanych pracach domowych, co znacznie podniosło wyniki nauczania uczniów ${ }^{22}$. Ale również warto skorzystać z propozycji praktycznego zastosowania mobilnych urządzeń w edukacji szkolnej zaproponowanych w cyklu publikacji pod redakcją Lechosława Hojnackiego: M-LEARNING, czyli (r)ewolucja w nauczaniu ${ }^{23}$ oraz M-LEARNING, czyli (r) ewolucja w uczeniu się ${ }^{24}$. W przewodnikach Autorzy przedstawili zbiór propozycji wykorzystania technologii mobilnych i rozmaitych aplikacji działających na tabletach i smartfonach, pomocnych zarówno w nauczaniu, jak i uczeniu się. Lista możliwych zastosowań tych urządzeń obejmuje między innymi prowadzenie blogów, obróbkę zdjęć oraz materiałów audio i wideo. Wśród ciekawych aplikacji znalazł się czytnik kodów kreskowych (QR Code), umożliwiający odczytywanie zaszyfrowanych danych tekstowych lub wizualnych nawiązujących do tematu lekcji. Podane $\mathrm{w}$ ten sposób polecenie z pewnością jest atrakcyjniejsze dla uczniów i doskonale koresponduje z zasadą nauki przez zabawę. Innym interesującym przykładem jest użycie aplikacji wykorzystujących systemy rozszerzonej rzeczywistości (ang. Augmented Reality - AR). Ich potencjał edukacyjny polega przede wszystkim na możliwości tworzenia poglądowych, bardzo realistycznych pomocy dydaktycznych, umożliwiających prezentowanie materiałów trudno dostępnych ze względów finansowych lub logistycznych.

Dzięki smartfonom można także zmodyfikować sposób utrwalania i sprawdzania wiedzy uczniów. Służą do tego bezpłatne platformy pozwalające na tworzenie i przeprowadzenie interaktywnych quizów, jak np. Kahoot! lub Quizizz. Uczeń udziela wówczas odpowiedzi na poszczególne pytania, dotykając właściwy przycisk na ekranie smartfonu. Przygotowanie quizu wymaga oczywiście poświęcenia czasu i pewnej wiedzy technicznej nauczyciela, jednak w zamian otrzymuje on zestawienie wyników wszystkich uczniów, ze wskazaniem poprawnie i błędnie udzielonych odpowiedzi. Pozwala to określić partie materiału, których opanowanie sprawia uczniom trudności.

Przedstawione propozycje stanowią jedynie przykłady użycia smartfonu jako narzędzia edukacyjnego wśród szerokiego spektrum różnorodnych możliwości, których wykorzystanie zależy przede wszystkim od inwencji samych zainteresowanych, czyli nauczycieli i uczniów.

${ }^{22}$ P. Bergman, Parent-Child Information Frictions and Human Capital Investment: Evidence from a Field Experiment, New York 2012, www.columbia.edu/ psb2101/BergmanSubmission.pdf [dostęp: 12.11.2016].

${ }^{23}$ L. Hojnacki (red.), M-LEARNING, czyli (r)ewolucja w nauczaniu, Warszawa 2011.

${ }^{24}$ L. Hojnacki (red.), M-LEARNING, czyli (r)ewolucja w uczeniu się, Warszawa 2013. 


\section{Konkluzje}

Procesy globalizacyjne i rozwój technologii informacyjnych znacząco zmieniły rzeczywistość społeczną, co domaga się nie tylko jakościowych przeobrażeń systemu szkolnego, lecz przede wszystkim zmiany mentalności nauczycieli. $W$ pewnym stopniu trudno jednak dziwić się oporowi nauczycieli przed stosowaniem smartfonów na lekcji, które wiążą się z jednej strony z brakiem odpowiednich kompetencji medialnych, $\mathrm{z}$ drugiej natomiast ze świadomością szkodliwego oddziaływania tegoż medium na rozwój psychofizyczny wychowanków. Z tymi obawami doskonale korespondują słowa Anthony'ego Giddensa, że

życie w świecie wysoko rozwiniętej nowoczesności jest jak rozpędzony moloch. Nie chodzi już tylko o bezustannie zachodzące zmiany. Sedno sprawy polega na tym, że te zmiany wykraczają poza wszelkie oczekiwania człowieka i wymykają się jego kontroli ${ }^{25}$.

Swobodny dostęp do informacji sprawił, że pozycja szkoły uległa deklasacji, co generuje nowy model kształcenia. Dlatego, współczesny nauczyciel powinien pogodzić się z faktem, że nie ma monopolu na wiedzę i zacząć współpracować, podjąć dialog z uczniami, celem wypracowania wspólnej przestrzeni edukacyjnej.

Zastosowanie smartfonów w edukacji - jak w przypadku każdej nowej technologii - spotyka się przede wszystkim z oporem ludzi. Uwydatnia się w tym przy padku duża przepaść między uczniami - zdigitalizowanymi odbiorcami a nauczycielami - cyfrowymi imigrantami ${ }^{26}$. W kwestii korzystania z urządzeń mobilnych, to nauczyciel może się wiele od uczniów nauczyć. Natomiast, przełamanie barier związanych z obawą o utratę autorytetu i zwrócenie się o pomoc do uczniów może stać się dla obu stron fascynującym doświadczeniem.

Należy podkreślić, iż włączenie technologii mobilnych w proces nauczania nie oznacza zastąpienia tradycyjnych środków nauczania. Niezbędna jest natomiast redefinicja ich roli w edukacji i zmiana programów nauczania, w których nacisk powinien być przeniesiony z nabywania kompetencji informatycznych, dobrze już uczniom znanych, na kształtowanie kompetencji informacyjnych, czyli umiejętności przetwarzania i krytycznej analizy informa-

${ }_{25}$ A. Giddens, Nowoczesność $i$ tożsamość. "Ja” i społeczeństwo w epoce późnej nowoczesności, przekł. A. Szulżycka, Warszawa 2002, s. 40.

${ }^{26}$ B. Woodcock, A. Middleton, A. Nortcliffe, Case Study. Considering the Smartphone Learner: an investigation into student interest in the use of personal technology to enhance their learning, Student Engagement and Experience Journal, 2012, 1(1), s. 5. 
$\mathrm{cji}^{27}$. Pozostaje jednak fakt, iż u progu XXI wieku edukacja odbywa się wciąż według systemu ukształtowanego jeszcze $\mathrm{w}$ wieku XIX, co nie daje podstaw sądzić, że dla pokolenia cyfrowego jest to droga optymalna.

\section{BIBLIOGRAFIA}

Abram S., Luther J., Born with the chip: The next generation will profoundly impact both library service and the culture within the profession, Library Journal, 2004, 129.

Bąk A., Korzystanie z urządzeń mobilnych przez małe dzieci w Polsce. Wyniki badania ilościowego, Fundacja Dzieci Niczyje, Warszawa 2015.

Batorski D., Korzystanie z technologii informacyjno-komunikacyjnych, [w:] Diagnoza społeczna 2011. Warunki i jakość życia Polaków. Raport, red. J. Czapiński, T. Panek, Rada Monitoringu Społecznego, Warszawa 2011.

Bergman P., Parent-Child Information Frictions and Human Capital Investment: Evidence from a Field Experiment, New York 2012, www.columbia.edu/ psb2101/BergmanSubmission.pdf [dostęp: 12.11.2016].

El-Hussein M.O.M., Cronje J.C., Defining Mobile Learning in the Higher Education Landscape, Educational Technology \& Society, 2010, 13(3), http://ifets.info/journals/13_3/3.pdf [dostęp: 14.11.216].

Federowicz M., Haman J., Herczyński J., Hernik K., Krawczyk-Radwan M., Malinowska K., Pawłowski M., Strawiński P., Walczak D., Wichrowski A., Czas pracy i warunki pracy w relacjach nauczycieli. Raport tematyczny z badania, Instytut Badań Edukacyjnych, Warszawa 2013.

Flick U., Projektowanie badania jakościowego, przekł. P. Tomanek, Wydawnictwo Naukowe PWN, Warszawa 2010.

"Generacja Z od A do Z". Rola nowych technologii w nauce i rozwoju dzieci w wieku 6-12 lat, Raport analityczny opracowany w 2015 roku przez Gemius Polska na zlecenie platformy edukacyjnej Squla.pl. http://di.com.pl/files/Raport_Generacja_Z_od_A_do_Z.pdf [dostęp: 12.11.2016].

Giddens A., Nowoczesność i tożsamość. "Ja" i społeczeństwo w epoce późnej nowoczesności, przekł. A. Szulżycka, Wydawnictwo Naukowe PWN, Warszawa 2002.

Hojnacki L. (red.), M-LEARNING, czyli (r)ewolucja w nauczaniu, Wydawnictwo Think Global, Warszawa 2011.

Hojnacki L. (red.), M-LEARNING, czyli (r)ewolucja w uczeniu się, Wydawnictwo Think Global, Warszawa 2013.

Hojnacki L., Pokolenie m-learningu - nowe wyzwanie dla szkoty, E-mentor, 2006, 1(13), http:/ / goo.gl/BMJLs. [dostęp: 12.11.2016].

Jachimowski M., Wptyw konwergencji mediów na kształtowanie się przestrzeni medialnej, Rocznik Prasoznawczy, 2012, 6.

Kabali H.K., Irigoyen M.M., Nunez-Davis R., Budacki J.G., Mohanty S.H., Leister K.P., Bonner R.L., Exposure and Use of Mobile Media Devices by Young Children, Pediatrics, 2015, 136(6), http://pediatrics.aappublications.org/content/early/2015/10/28/peds.2015 -2151 [dostęp: 11.10.2016].

${ }^{27}$ D. Batorski, Korzystanie z technologii informacyjno-komunikacyjnych, [w:] Diagnoza społeczna 2011. Warunki i jakość życia Polaków. Raport, red. J. Czapiński, T. Panek, Warszawa 2011, s. 325. 
Kukulska-Hulme A., Traxler J., Mobile learning: a handbook for educators and trainers, Taylor \& Francis, New York 2005.

McCrindle M., Wolfinger E., The ABC of XYZ: understanding the global generations, McCrindle Research Pty, Bella Vista 2014.

Mcluhan E., Zingrone F. (red.), M. McLuhan. Wybór tekstów, przekł. E. Różalska, J.M. Stokłosa, Zysk i S-ka Wydawnictwo, Poznań 2001.

McNeal J.U., The Kids Market: Myths and Realities, Paramount Market Publishing, New York 1999.

Prensky M., Digital Natives, Digital Immigrants, Part 1, On the Horizon, 2001, 9(5).

Saldik S.L., The New Recruit: What your Association needs to know about X, Y \& Z, MN: Expert Publishing, Andover 2007.

Small G.W., Vorgan G., iBrain: Surviving the Technological Alteration of the Modern Mind, Collins Living, New York 2008.

Susłow W., Królikowski T., M -learning, więc uczenie się w terenie, Zeszyty Naukowe Politechniki Poznańskiej, 2005, 8.

Williams A., Meet Alpha: The Next 'Next Generation', “The New York Times” z 19.09.2015. https:/ / www.nytimes.com/2015/09/19/fashion/meet-alpha-the-next-next-generation.html?_r=0 [dostęp: 7.10.2016].

Woodcock B., Middleton A., Nortcliffe A., Case Study. Considering the Smartphone Learner: an investigation into student interest in the use of personal technology to enhance their learning, Student Engagement and Experience Journal, 2012, 1(1). 